\section{Temporal ultrasound for monitoring tocilizumab treatment in giant cell arteritis: seeing beyond serum markers?}

We read with great interest the letter of Nannini et al, which addressed the issue of treatment interruption in giant cell arteritis (GCA) patients treated with tocilizumab (TCZ) and the use of 18-fluorodeoxyglucose positron emission tomography (FDGPET) for disease monitoring and relapse predicting. ${ }^{1}$ In this study, FDG-PET examination after 2 months of TCZ discontinuation (14 months after treatment initiation) could identify those large-vessel GCA (LV-GCA) patients who would experience a relapse later, despite having normal inflammation markers. Interestingly, FDG-PET findings after 6 months of TCZ therapy were not significantly improved in patients who relapsed after TCZ discontinuation, in contrast to what was observed for those who maintained remission. ${ }^{1}$ According to authors, this imaging modality could be a useful monitoring and prognostic tool for patients with LV-GCA.

GCA, a type of large-size and medium-size vessel vasculitis, usually affects people over 50 years old. Two subtypes have been identified; namely cranial GCA and LV-GCA. Over the last years, ultrasound (US) of temporal arteries has been increasingly recognised as a first-line diagnostic tool for cranial GCA, while magnetic-resonance angiography and FDG-PET are utilised for the diagnosis of LV-GCA. Moreover, randomised controlled trials in GCA patients have shown that the addition of TCZ to corticosteroids induces disease remission and offers faster steroid sparing and reduced relapse rate. On the other hand, nearly one-third of patients treated with TCZ might experience a disease flare after treatment discontinuation, ${ }^{1}$ while clinical and serological parameters might fail to reveal a disease relapse. ${ }^{2}$ In addition, TCZ treatment leads to a fall of inflammation markers that sometimes does not reflect disease activity. ${ }^{3}$ Due to the lack of reliable serological marker for these patients, imaging modalities emerge as possible monitoring and prognostic tools. Repeated biopsies for disease monitoring are not feasible in clinical practice.

Regarding the cranial form of GCA, FDG-PET is high-cost, has low availability, exposes the patient to ionising radiation and has questionable sensitivity in this form of the disease. In contrast, US has low cost, is generally available, bears no radiation and offers acceptable sensitivity in the detection of vessel wall inflammation in temporal arteries. On this basis, serial US examinations might be useful for the monitoring of TCZ treatment.

The experience about temporal US in cranial GCA patients treated with TCZ is limited. Vitiello et al reported two cases in which initiation of TCZ treatment led to disappearance of 'halo sign' in the temporal US. ${ }^{4}$ In our clinic, TCZ resulted in significant amelioration of vessel wall inflammation in two cases. TCZ was initiated in a 62-year-old woman with cranial GCA. The baseline temporal US revealed a hypoechoic halo sign in both superficial common temporal arteries (figure 1A). A new temporal US 3 months later showed decrease of the hypoechoic area in the vessel wall, while clinical and serological improvement was evident (figure 1B). After 12 months of TCZ treatment, the patient is in disease remission and the hypoechoic findings in the vessel wall have almost disappeared (figure 1C). Additionally, in an 85-year-old woman with cranial GCA, TCZ led to improvement of the hypoechoic appearance of the inflamed vessel wall, as depicted in a new temporal US

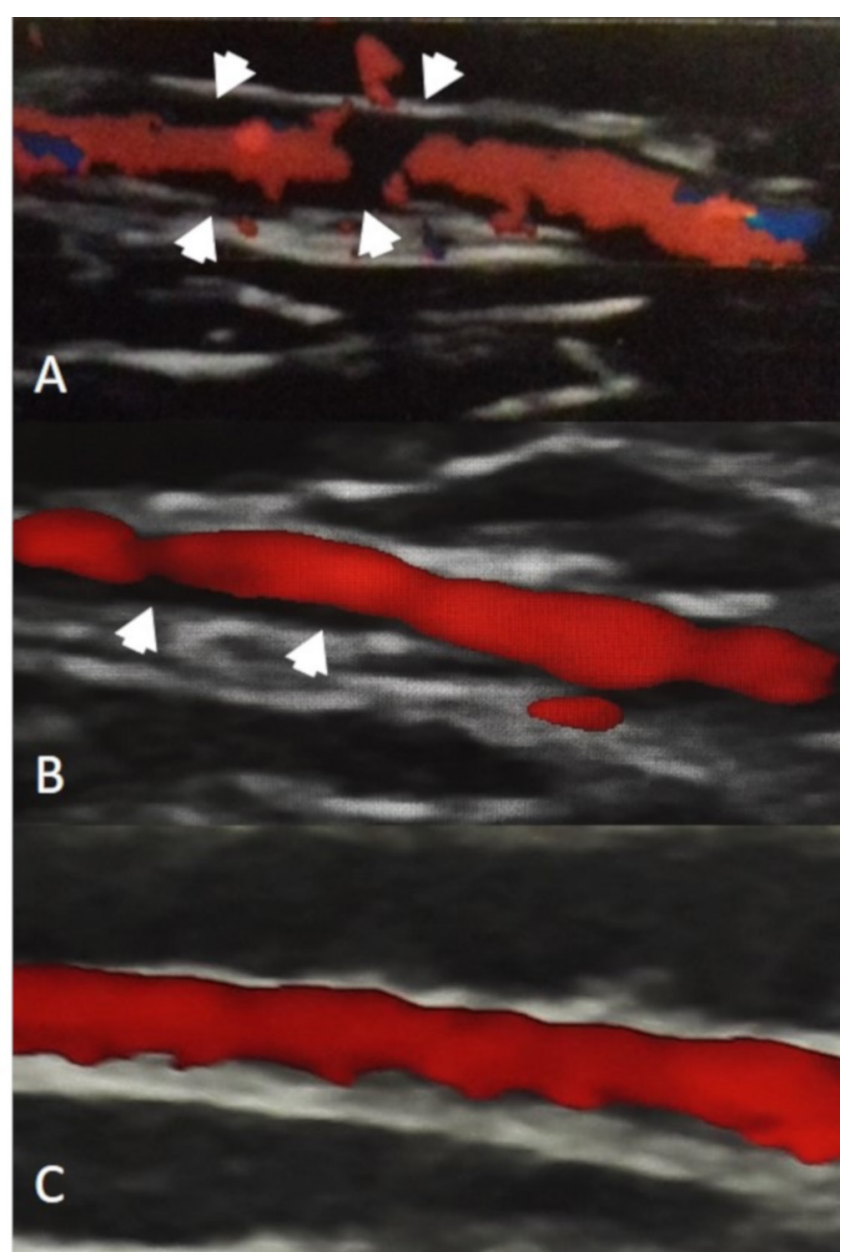

Figure 1 Ultrasound of the right superficial common temporal artery (longitudinal view) at baseline (A), 3 months later (B) and 12 months after (C) consecutive tocilizumab treatment. At baseline (A), a dark hypoechoic area can be noted at the vessel wall (arrows). Three months later, the 'halo sign' has been improved (B) and after 12 months it has almost disappeared (C). Meanwhile, serum inflammation markers and patient's symptoms have significantly improved. A linear probe $(12 \mathrm{~L})$, $12 \mathrm{MHz}$ (grey scale) and 6.7 MHz (colour Doppler) frequency were used.

performed 3 months after treatment commencement, compared with baseline.

As for LV-GCA, the wall of large vessels might remain thickened for months despite therapy, but an increase in intima-media complex, as observed by US, suggests treatment failure. ${ }^{5}$ It has been reported that contrast-enhanced US can detect disease flares in patients treated with TCZ for Takayasu arteritis, but this US technique has not been extensively studied yet. Therefore, the use of US in the monitoring of patients with LV-GCA is still under debate. Based on the letter of Nannini et al, FDGPET might be useful in monitoring TCZ-treated patients with LV-GCA. A question arising is whether findings in US parallel the changes depicted in FDG-PET. We believe that a comparative study addressing this issue would be of great interest.

Recently, the role of US in the follow-up of GCA patients has emerged. ${ }^{6}$ As US is an operator-dependent examination, the objectivity of repetitive examinations is questionable and the technical parameters should be precisely determined. Awaiting further prospective studies, we suggest that temporal US can be an appealing choice for monitoring disease activity in cranial GCA patients treated with TCZ. 
Gerasimos Evangelatos $\odot,{ }^{1}$ George E Fragoulis $\odot,{ }^{2}$ Alexios Iliopoulos ${ }^{1}$

${ }^{1}$ Rheumatology Department, 417 Army Share Fund Hospital (NIMTS), Athens, Greece ${ }^{2}$ Rheumatology Unit, First Department of Propaedeutic Internal Medicine, School of Medicine, National and Kapodistrian University of Athens, Athens, Greece

Correspondence to Dr Gerasimos Evangelatos, Rheumatology Department, 417 Army Share Fund Hospital (NIMTS), 11521 Athens, Greece; gerevag@gmail.com

Twitter George E Fragoulis@FragoulisGeorge

Contributors GE: performed the ultrasound examinations, took photo of the ultrasounds, participated in literature search and manuscript preparation, approved the final version of the manuscript. GEF: participated in literature search and manuscript preparation, approved the final version of the manuscript. Al: participated in manuscript preparation and approved the final version of the manuscript.

Funding The authors have not declared a specific grant for this research from any funding agency in the public, commercial or not-for-profit sectors.

Competing interests None declared.

Patient consent for publication Not required.

Provenance and peer review Not commissioned; internally peer reviewed.

(c) Author(s) (or their employer(s)) 2021. No commercial re-use. See rights and permissions. Published by BMJ.

A) Check for updates
To cite Evangelatos G, Fragoulis GE, Iliopoulos A. Ann Rheum Dis 2021;80:e184.

Received 23 October 2019

Accepted 30 October 2019

Published Online First 5 November 2019

Ann Rheum Dis 2021;80:e184. doi:10.1136/annrheumdis-2019-216527

\section{ORCID iDs}

Gerasimos Evangelatos http://orcid.org/0000-0003-3822-3093

George E Fragoulis http://orcid.org/0000-0003-4932-7023

\section{REFERENCES}

1 Nannini C, Niccoli L, Sestini S, et al. Remission maintenance after tocilizumab dosetapering and interruption in patients with giant cell arteritis: an open-label, 18-month, prospective, pilot study. Ann Rheum Dis 2019;78:1444-6.

2 Adler S, Reichenbach S, Gloor A, et al. Risk of relapse after discontinuation of tocilizumab therapy in giant cell arteritis. Rheumatology 2019;58:1639-43.

3 Stone JH, Tuckwell K, Dimonaco S, et al. Glucocorticoid dosages and acute-phase reactant levels at giant cell arteritis flare in a randomized trial of tocilizumab. Arthritis Rheumatol 2019:71:1329-38.

4 Vitiello G, Orsi Battaglini C, Carli G, et al. Tocilizumab in giant cell arteritis: a real-life retrospective study. Angiology 2018;69:763-9.

5 Schmidt WA. Ultrasound in the diagnosis and management of giant cell arteritis. Rheumatology 2018;57:ii22-31.

6 Monti S, Floris A, Ponte CB, et al. The proposed role of ultrasound in the management of giant cell arteritis in routine clinical practice. Rheumatology 2018;57:112-9. 